\title{
FATORES DETERMINANTES DA EFICIÊNCIA DOS CLUBES DE FUTEBOL DO BRASIL
}

\author{
Marke Geisy da Silva Dantas ${ }^{1}$ \\ Márcio André Veras Machado ${ }^{2}$ \\ Marcelo Alvaro da Silva Macedo ${ }^{3}$
}

Resumo: O objetivo desta pesquisa é avaliar quais são os fatores determinantes da eficiência dos clubes de futebol brasileiros. A presente pesquisa se utiliza das demonstrações contábeis e de outros dados de 36 clubes de futebol brasileiros no período de 2010 a 2012. Para o cálculo da eficiência, o modelo escolhido foi o Super-efficiency DEA, tendo como insumo a despesa do futebol de cada clube, enquanto os produtos são a Receita Operacional e a Pontuação estabelecida pela CBF na confecção de seu Ranking. O modelo BCC (Retorno Variável de Escala) foi utilizado com orientação ao output. Para atingir o objetivo proposto, os indicadores de eficiência serão considerados como variável dependente de um modelo de Regressão Tobit. As variáveis independentes escolhidas são "Grau de Endividamento", "Títulos", "Divisão", "12 grandes clubes", "Acesso ou Libertadores", "Rebaixamento,, "Aproveitamento de Pontos" e "Passivo a Descoberto". O resultado da regressão indica que apenas "Títulos" e "Divisão" possuem significâncias estatísticas com os indicadores de eficiência. Ou seja, clubes que conquistam títulos em determinada temporada e clubes da primeira divisão são mais eficientes que os demais. Os resultados desta pesquisa podem ser um ponto de partida para o desenvolvimento de novos estudos que tenham como objetivo a análise financeira e operacional dos clubes de futebol no Brasil, que é ainda escassa, além de auxiliar os clubes no controle de gastos, como também na busca de novas fontes de receitas.

Palavras-chave: Clubes de Futebol. Super-Eficiência. Títulos.

\footnotetext{
1 E-mail: markegeisy@hotmail.com. Universidade Federal do Rio Grande do Norte/Professor Substituto.

2 E-mail: mavmachado@hotmail.com. Universidade Federal da Paraíba.

${ }^{3} 3$ E-mail: malvaro.facc.ufrj@gmail.com. Universidade Federal do Rio de Janeiro.

- DOI: http://dx.doi.org/10.14392/asaa.2015080106

- Artigo recebido em 07/09/2014. Aprovado em 25/04/2015.
} 


\title{
FACTORS OF DETERMINANTS EFFICIENCY OF BRAZIL FOOTBALL CLUBS
}

\begin{abstract}
The aim of this research is to assess what are the determinants factors of the efficiency of Brazilian soccer clubs. This research uses financial statements from 36 Brazilian soccer clubs, in the period 2010 to 2012. The model chosen to calculate the efficiency was the super-efficiency DEA, taking as input the football expense, while the products are Operational Revenue and Score established by the CBF in its rank. The BCC (Variable Return to Scale) was used together with the output orientation. The efficiency indicators will be considered as a dependent variable of Tobit regression model. The independent variables chosen are "Degree of Debt", "Champion", "League", "12 big clubs", "Access or Libertadores", "Downgrade", "Percentage of Points" and "Unsecured Liabilities". The regression results indicate that only "Champion" and "League" have statistical significance with efficiency indicators. The clubs that win championships and the first league clubs are more efficients. Our results can be a starting point for the development of new studies that aim to financial and operational analysis of brazilian soccer clubs and assist clubs in control spending.
\end{abstract}

Keywords: Football Clubs. Super-Efficiency. championships.

\section{INTRODUÇÃO}

O s clubes profissionais de futebol são empresas que estão fora da normalidade, pois seu desempenho é julgado dentro e fora de campo. A presença de objetivos não financeiros levanta a questão de como medir o desempenho dos clubes (Gúzman, Morrow, 2007). Existe hoje uma preocupação maior dessas entidades em aliar gastos com o desempenho da organização, tanto na questão econômico-financeira, quanto na maximização das conquistas esportivas. Portanto, conhecer a eficiência dos investimentos tornou-se um dos objetivos dos estudiosos do futebol.

O investimento no futebol é alto. Clubes grandes têm a tendência a investir mais. Mas, os objetivos podem não lograr êxito. Por exemplo, uma equipe pode alcançar triunfos esportivos, usando recursos além do que é necessário, enquanto outra equipe com recursos mais modestos podem atingir os resultados esperados (Espitia-Escuer, García-Cebrián, 2010). Essa relação entre insumos e produtos/ resultado pode demonstrar a eficiência dos investimentos dos clubes de futebol, principalmente em relação ao desperdício de recursos, como também a manutenção do equilíbrio financeiro dos clubes.

Ademais, além de gerar desperdícios, os altos investimentos também são capazes de colocar um clube em dificuldades financeiras, tanto a curto, quanto a longo prazo. Mediante este fato, alguns fatores podem estar aliados ao nível de eficiência. O maior problema, segundo Jardin (2009), é que a medição de eficiência no esporte, principalmente no futebol, é um desafio, já que é difícil identificar realmente quais são os objetivos de um clube, como também quais são os principais recursos.

Anteriormente, a medição de desempenho dos clubes era pautada no quesito esportivo. Com o advento do conceito de clube-empresa, o lado financeiro do desempenho também se tornou impor- 
tante, principalmente no tocante a análise de investimentos realizados e o seu impacto nos resultados esportivos, como também em outros indicadores financeiros. Daí, segundo Dantas (2013), surge alguns questionamentos: será que a contratação de certos atletas acarretou em títulos ou um bom desempenho? Os investimentos melhoraram o desempenho financeiro da entidade, com o aumento de bilheteria, patrocínios e premiações?

Barros, Assaf e Sá-Earp (2010) também afirmam que a literatura atual já reconheceu a importância de combinar esportes e resultados financeiros como parte dos objetivos da gestão esportiva. Por isso, não surpreende o número de estudos recentes que se concentram na eficiência dos clubes. Segundo Dantas (2013), há um interesse crescente - e recente - na análise econômica do esporte especialmente em atividades como o rúgbi, o beisebol, basquete e Futebol Americano. Conforme Garcia-Sanchéz (2007), três motivos explicam o interesse recorrente na área: a emoção associada à atividade esportiva; a importância financeira e peculiaridades da indústria; e a disponibilidade dos dados.

Ainda segundo Dantas (2013), alguns estudos relacionam outras variáveis com os indicadores de eficiência, citando como exemplo as pesquisas de Barros, Assaf e Sá-Earp (2010) e Halkos e Tzeremes (2013). Neste caso, o autor cita que fatores como o tamanho (em termos de importância do clube), títulos conquistados, endividamento, a divisão da liga e outras variáveis podem explicar a variação dos indicadores de eficiência.

O presente estudo passa a adentrar em outra vertente (sem abandonar a vertente da eficiência), que é a tentativa de relacionar outros aspectos que norteiam esse setor da economia, como indicadores contábeis e outras variáveis de desempenho. Além disso, os clubes brasileiros de futebol ainda são pouco explorados em pesquisas brasileiras, no que tange o cálculo de indicadores de eficiência. Diante de tal fato, ainda não existem pesquisas nacionais que trazem em seu escopo a relação de significância entre os indicadores de eficiência e outras variáveis, prática difundida nos estudos da DEA em âmbito internacional. Assim, apresenta-se o problema de pesquisa: quais os fatores determinantes da eficiência dos clubes de futebol no Brasil?

O objetivo desta pesquisa é avaliar quais os fatores determinantes da eficiência dos clubes de futebol no Brasil. Desse modo, este estudo se diferencia de vários estudos anteriormente feitos no Brasil que de maneira geral procuraram analisar a questão da transparência, seja por meio da análise de evidenciação e/ou das práticas de governança corporativa por parte dos clubes brasileiros de futebol. Este é o caso dos estudos de Rezende, Dalmácio e Salgado (2010) e de Silva e Carvalho (2009), que trataram da questão da evidenciação, e do estudo de Rezende, Facure e Dalmácio (2009) que tratou da questão da governança corporativa. Cabe ressaltar que em relação aos estudos com clubes de futebol brasileiros o presente estudo segue na mesma linha do trabalho de Barros, Assaf e Sá-Earp (2010), se diferenciando do mesmo em termos temporais e metodológicos, já que o presente estudo não só analisa o desempenho, mas também procura identificar seus determinantes.

$O$ artigo se divide em seis partes: A primeira é esta, que compreende a Introdução. A segunda trata-se da Revisão da Literatura. A Metodologia é a terceira, que compreende as técnicas utilizadas na pesquisa, enquanto a Análise de Dados, a quarta, compreende a estatística descritiva das variáveis, o 
cálculo do modelo DEA e os resultados da regressão. Por fim, apresentam-se as Considerações Finais e as Referências que subsidiam este estudo.

\section{REVISÃO DE LITERATURA}

\subsection{ASPECTOS ECONÔMICOS DO FUTEBOL}

Neale (1964) já admitia que a principal peculiaridade da economia relacionada ao esporte é que as rendas dependem da competição entre as equipes. Kern, Schwarzmann e Wiedenegger (2012) apontam que as duas principais operações em clube de futebol são: (1) criar uma equipe altamente competitiva com uma determinada quantidade de dinheiro; e (2) transformar o potencial do time em sucesso esportivo e, consequentemente, em aumento da receita.

Barajas, Fernández-Jardón e Crolley (2007) observam que as receitas não são controladas como em outros setores, pois, em relação ao esporte, o desempenho esportivo possui um grande impacto sobre o faturamento. Porém, os custos e despesas podem ser facilmente controlados e o melhor controle sobre eles leva ao lucro. Se não existir uma política de equilíbrio nos custos, há pouca chance de rentabilidade. Assim, de acordo com a proposição citada, o sucesso esportivo e o sucesso financeiro estão intimamente ligados, como citam também Espitia-Escuer e García-Cebrian (2010): um clube sobrevive se aumenta os lucros, e estes aumentam se há aumento de renda, o que é conseguido através de direitos de transmissão de jogos e vendas de mais ingressos a partir do sucesso dos clubes.

Portanto, dada a inter-relação entre os resultados desportivos e os lucros, e para não comprometer a renda das temporadas seguintes, a conduta adequada seria a de maximizar os resultados desportivos de cada temporada. Mesmo assim, os recursos não devem ser utilizados de forma desnecessária. Portanto, a maximização do lucro de clubes de futebol repousa sobre a eficiência com que eles executam os seus objetivos.

Conforme Garcia-Sanchéz (2007), todas as questões discutidas são baseadas em conceitos econômicos centrais, principalmente em relação à eficiência e eficácia, devendo também ser levado em consideração o fato de que a importância econômica da indústria do futebol é constituída pelo poder emocional dos fãs, que é impulsionado pelo nível de sucesso da equipe.

\subsection{ESTUDOS ANTERIORES}

Como dito anteriormente, existem vários estudos envolvendo clubes brasileiros de futebol, porém são poucos os que têm foco no desempenho dos mesmos. Este é o caso do estudo realizado por Rezende, Dalmácio e Salgado (2010), onde os autores que procuraram analisar o nível de disclosure dos clubes brasileiros em relação às demonstrações financeiras, entre o período de 2001 a 2007. Os principais resultados mostram que o tratamento contábil difere e utiliza critérios variados para diversas informações, além de que o nível de evidenciação está correlacionado ao tamanho econômico dos clubes. O cluster com maior score de evidenciação é formado por São Paulo, Corinthians e Palmeiras.

Além disso, Silva e Carvalho (2009) também analisaram a evidenciação dos clubes de futebol do Brasil, com o intuito de mensurar o nível de evidenciação e o seu grau de relacionamento com o desempenho financeiro e esportivo dos clubes analisados. A evidenciação foi medida por seis critérios: Forma e Disposição das Demonstrações Contábeis, Notas Explicativas, Quadros e Demonstrações Suplementares, Demonstrações Complementares, Parecer dos Auditores Independentes, e Relatório 
da Administração. Os resultados indicaram que os clubes com maior grau de evidenciação também apresentam melhores resultados no campo (ranking CBF) e em termos financeiros (resultado da DRE).

Por fim, outro exemplo de pesquisa realizada nos clubes brasileiros de futebol é o estudo de Rezende, Facure e Dalmácio (2009) que avalia o nível de governança corporativa dos clubes. Os autores ressaltaram que o maior índice de governança obtido, não ultrapassou 45,1\%, com uma média nacional dos clubes pesquisados de $28,7 \%$. Foram constatados ainda indícios de gerenciamento de resultados, não reconhecimento de dívidas, falta de critérios quanto ao reconhecimento de possíveis perdas e utilização de práticas condenadas pelos contadores, o que corrobora com o "cenário caótico de escândalos dentro do futebol brasileiro".

Porém, existem alguns estudos internacionais e apenas um brasileiro, que tiveram como foco a questão do desempenho. A Figura 1 apresenta o resumo dos estudos que se utilizam de técnicas não paramétricas, como é o caso do presente estudo, para estudar a eficiência dos clubes de futebol.

Figura 1: Resumo dos trabalhos que aliam eficiência e futebol

\begin{tabular}{|c|c|c|c|c|}
\hline Autor & Amostra/Período & Insumos & Produtos & Técnica \\
\hline Haas (2003) & $\begin{array}{l}\text { Major League Soccer - } \\
2000\end{array}$ & Salários dos jogadores e do treinador & $\begin{array}{c}\text { Pontos, total de espectadores } \\
\text { e receita }\end{array}$ & DEA - BCC e CCR \\
\hline Haas (2003) & $\begin{array}{l}\text { English Premier League ( } 20 \\
\text { clubes) }-2000 / 01\end{array}$ & $\begin{array}{l}\text { Total dos salários dos jogadores; } \\
\text { salário do treinador; população da } \\
\text { cidade que reside a equipe }\end{array}$ & $\begin{array}{c}\text { Pontos, total de espectadores } \\
\text { e receita }\end{array}$ & DEA - BCC e CCR \\
\hline Barros e Leach (2006) & $\begin{array}{l}\text { English Premier League } \\
\text { (12 Cubes) }-1998 / 99 \text { a } \\
2002 / 03\end{array}$ & $\begin{array}{l}\text { Número de jogadores; Salários; } \\
\text { ativos líquidos e Gastos com as } \\
\text { instalações dos estádios }\end{array}$ & $\begin{array}{l}\text { Pontos obtidos no campeonato; } \\
\text { público e volume de receitas }\end{array}$ & $\begin{array}{c}\text { DEA (CCR e BCC) - orientado a } \\
\text { output }\end{array}$ \\
\hline $\begin{array}{l}\text { Guzmán e Morrow } \\
\text { (2007) }\end{array}$ & $\begin{array}{l}\text { English Premier League - } \\
\text { 1997/98 a 2002/03 }\end{array}$ & $\begin{array}{l}\text { Custos de Staff; outras despesas; } \\
\text { remuneração dos diretores }\end{array}$ & $\begin{array}{c}\text { Pontos conquistados na } \\
\text { temporada e total de receitas } \\
\text { do ano }\end{array}$ & $\begin{array}{l}\text { DEA-Malmquist com análise de } \\
\text { correlação canônica (CCA), que } \\
\text { fora usada para garantir a coesão } \\
\text { das variáveis de entrada e saída }\end{array}$ \\
\hline Jardin (2009) & $\begin{array}{l}\text { French football clubs } \\
\text { (Ligue 1) - } 2004 \text { a } 2007\end{array}$ & $\begin{array}{c}\text { Total dos salários dos jogadores; } \\
\text { população da cidade que reside a } \\
\text { equipe }\end{array}$ & $\begin{array}{c}\text { Número de pontos da } \\
\text { temporada e volume de receitas }\end{array}$ & DEA-Malmquist \\
\hline $\begin{array}{l}\text { Barros, Assaf e Sá- } \\
\quad \text { Earp (2010) }\end{array}$ & $\begin{array}{c}20 \text { Times do Brasil - } 2006 \\
\text { e } 2007\end{array}$ & $\begin{array}{l}\text { O custo operacional (excluindo os } \\
\text { custos do trabalho), ativo total, e da } \\
\text { folha de pagamento da equipe }\end{array}$ & $\begin{array}{l}\text { Público, receitas totais, e pontos } \\
\text { em um campeonato }\end{array}$ & $\begin{array}{l}\text { DEA - bootstrap - variáveis } \\
\text { independentes como vitórias, } \\
\text { derrotas, número de gols feitos, } \\
\text { número de gols sofridos, dummy } \\
\text { de região e para tamanho }\end{array}$ \\
\hline $\begin{array}{l}\text { Barros e Garcia-del- } \\
\quad \text { Barrio (2011) }\end{array}$ & $\begin{array}{l}\text { Amostra representativa } \\
\text { dos clubes espanhóis - } \\
\text { 1996/97 a 2003/04 }\end{array}$ & $\begin{array}{l}\text { O custo operacional (excluindo os } \\
\text { custos do trabalho), ativo total, e da } \\
\text { folha de pagamento da equipe }\end{array}$ & $\begin{array}{l}\text { Receita de público e outras } \\
\text { receitas }\end{array}$ & $\begin{array}{c}\text { DEA-bootstrap -Sistema de jogo, } \\
\text { jogadores, casa e estrangeiros } \\
\text { foram as variáveis exógenas }\end{array}$ \\
\hline $\begin{array}{l}\text { Soleimani-Damaneh, } \\
\text { Hamidie Sajadi (2011) }\end{array}$ & $\begin{array}{l}\text { Iranian primer football } \\
\text { league - } 2009 / 10\end{array}$ & Ativos Fixos, Salários & $\begin{array}{c}\text { Pontos na liga, número de } \\
\text { espectadores e a renda no fim } \\
\text { da temporada }\end{array}$ & $\begin{array}{c}\text { DEA e Analytical Hierarchy } \\
\text { Process (AHP) - BCC orientado } \\
\text { a input }\end{array}$ \\
\hline $\begin{array}{l}\text { Kern, Schwarzmann e } \\
\text { Wiedenegger (2012) }\end{array}$ & $\begin{array}{l}\text { English Premier League - } \\
\text { 2006/07 a 2008/09 }\end{array}$ & $\begin{array}{l}\text { Primeiro estágio: Custos salariais, } \\
\text { atividade líquida de transferência. } \\
\text { Segundo estágio: Valor de mercado }\end{array}$ & $\begin{array}{l}\text { Primeiro estágio: valor de } \\
\text { mercado. Segundo estágio: } \\
\text { Receitas, Público e Sucesso } \\
\text { esportivo (segundo estágio) }\end{array}$ & $\begin{array}{c}\text { DEA (BCC e CCR, eficiência de } \\
\text { escala) }\end{array}$ \\
\hline $\begin{array}{l}\text { Halkos e Tzeremes } \\
\text { (2013) }\end{array}$ & $\begin{array}{l}25 \text { maiores clubes } \\
\text { europeus - } 2009 \text {-Forbes }\end{array}$ & Receitas & $\begin{array}{l}\text { Output composto pela soma } \\
\text { dos números de campeonatos } \\
\text { conquistados ponderados }\end{array}$ & $\begin{array}{l}\text { DEA-bootstrap + Regressão } \\
\text { truncada- determinantes: Valor } \\
\text { corrente e endividamento }\end{array}$ \\
\hline
\end{tabular}

Fonte: Elaborado pelo autor.

Além de calcular a eficiência, alguns desses trabalhos apresentaram outras metodologias em conjunto com a Análise Envoltória de Dados (DEA), com o intuito de identificar variáveis que possam explicar os indicadores encontrados. Halkos e Tzeremes (2013) aplicaram a DEA nos principais clubes da Europa, com os dados da revista Forbes, referente ao ano de 2009, investigando se o valor do clube e/ 
ou as dívidas influenciam em seu desempenho, através de uma regressão truncada. Os autores utilizaram como input a Receita do período, enquanto o output foi uma soma ponderada dos campeonatos disputados, conforme a Figura 1. Antes do bootstrap, o clube mais eficiente foi o Real Madrid e, após o procedimento citam como mais eficientes Juventus, Milan, Glasgow Rangers, Celtic e Aston Villa. Os resultados da regressão truncada revelam que o sinal negativo no coeficiente do valor corrente indica que um alto valor não garante melhor desempenho. Ao mesmo tempo, a evidência empírica sugere que os níveis de dívida dos clubes de futebol não influenciam os seus níveis de eficiência.

Barros, Assaf e Sá-Earp (2010) estudaram 20 clubes brasileiros participantes do campeonato brasileiro da Série A, do ano de 2007. Aplicaram o DEA-bootstrap, utilizando como produtos "número de torcedores", "total das receitas" e "pontos no campeonato brasileiro", enquanto que as entradas são os "custos operacionais" (excluindo custos de trabalho), "ativo total" e a "folha de pagamento da equipe". No modelo tradicional, quatro clubes são apontados como eficiente (Grêmio, São Paulo, São Caetano e Vitória). No entanto, quando se considera os resultados do bootstrap, nenhum dos clubes de futebol se encontra na fronteira.

Em termos de desempenho médio do campeonato brasileiro, ambos os métodos indicam que os clubes brasileiros operam em um alto nível de ineficiência. No tocante aos resultados da regressão truncada, o"tamanho" e a"cidade do clube" parecem não ter importância na eficiência. Tal achado pode ter resultado do contexto único do campeonato brasileiro, onde a maioria dos clubes e, especialmente, os grandes, sofrem com enormes dívidas e, assim, não podem colher o benefício de economias de escala. Os autores também demonstraram que a eficiência aumenta com vitórias e gols marcados e decresce com as derrotas e gols sofridos.

Barros e Garcia-del-Barrio (2011) avaliam os clubes espanhóis no período de 1996 a 2004. No primeiro estágio, utilizaram a DEA bootstrap e no segundo estágio uma regressão truncada. O clube com maior eficiência foi o Barcelona. Os achados da regressão demonstraram que uma estratégia mais defensiva implica em aumento do nível de eficiência, como também quando o número de jogadores caseiros e estrangeiros cresce. Os autores indicam que os dois grandes da Espanha (Real Madrid e Barcelona) contribuem para o aumento do nível de eficiência e, ainda apontam os dois como os principais clubes.

Barros, Corral e Prieto-Rodriguez (2008) afirmam que uma característica importante na literatura sobre a eficiência no esporte é a de que quase todos os estudos já feitos negligenciaram a existência de heterogeneidade dos dados, assumindo que todos os clubes utilizam a mesma tecnologia. Barros e Garcia-del-Barrio (2011) relatam que, apesar das pesquisas acadêmicas já realizadas, as descobertas empíricas permanecem inconsistentes e discutíveis sobre as causas e efeitos da eficiência, além da falta de consistência dos resultados sobre a eficiência esportiva.

\section{METODOLOGIA}

A pesquisa em questão se utiliza das demonstrações contábeis de 36 clubes de futebol brasileiros (ABC-RN, América-MG, Atlético-MG, ASA-AL, Atlético-PR, Avaí, Bahia, Botafogo, Bragantino, Corinthians, Coritiba, Criciúma, Cruzeiro, Figueirense, Flamengo, Fluminense, Goiás, Grêmio, Grêmio Barueri, Guarani, Internacional, Joinville, Náutico, Palmeiras, Paraná, Ponte Preta, Portuguesa, Santa Cruz-PE, Santo André, Santos, São Caetano, São Paulo, Sport, Vasco, Vila Nova-GO e Vitória) disponíveis na internet. Foram coletadas as demonstrações referentes ao período de 2010 a 2012.

O objetivo era analisar as demonstrações dos primeiros 50 clubes do ranking da CBF (no período de 2008 a 2012), mas, por falta de divulgação dos mesmos, ou por falta de padronização e de divulgação 
dos dados de alguns, a amostra final se estabeleceu em 36 clubes, nos anos de 2010, 2011 e 2012. Assim, a amostra será não-probabilística, escolhida pela disponibilidade de obtenção das demonstrações contábeis.

No caso deste estudo, o modelo de análise de eficiência escolhido será Super-efficency DEA (ou Super-eficiência). O modelo de Super-eficiência, proposto por Andersen e Petersen (1993), de acordo com Chen (2004, p. 213), pode ser usado para classificar o desempenho de Unidades Tomadoras de Decisão (DMUs - Decision Making Units), principalmente daquelas que se encontram na fronteira de eficiência. Segundo Andersen e Petersen (1993), na Super-eficiência não há limites para a eficiência das DMUs, podendo ultrapassar o valor "1".

O retorno de escala escolhido é o BCC (Retornos Variáveis de Escala) com orientação ao output. Esta escolha foi realizada para minimizar o efeito da disparidade entre os dados dos clubes de futebol, por conta da diferença de tamanhos existente. Em relação à orientação, a escolha entre input e output parte da teoria que baseia o estudo. No caso dos clubes (e da pesquisa em questão), o input escolhido é o gasto diretamente ligado ao futebol. A despesa representa salários, viagens, etc. Para esta pesquisa, parte-se do pressuposto de que os clubes de futebol estão mais propensos a maximizar os resultados conquistados (tanto financeiramente, quanto esportivamente), do que tentar minimizar os custos, já que os clubes necessitam gastar para montar bons times e se tornarem competitivos.

Assim, como resultados principais de uma entidade do setor esportivo, como são os clubes de futebol, apresentam-se as receitas e o desempenho esportivo per se, produtos demonstrados e estudados em pesquisas descritas na Figura 1. Os inputs e outputs utilizados são descritos na Figura 2.

Os "custos/despesas do departamento do futebol" são uma conta da Demonstração do Resultado do Exercício que abrange salários, viagens, alimentação, etc. A "receita operacional" é formada por receitas de bilheteria, patrocínios, direitos de transmissão, venda de direitos federativos, licenciamentos, etc, todas ligadas à questão operacional. A receita também foi retirada das Demonstrações de Resultado do Exercício.

Figura 2: Inputs e outputs escolhidos para análise

\begin{tabular}{|c|c|c|}
\hline Input 1 & Output 1 & Output 2 \\
\hline $\begin{array}{c}\text { Despesas Operacionais (variável } \\
\text { retirada da Demonstração do } \\
\text { Resultado do Exercício) }\end{array}$ & $\begin{array}{c}\text { Receita Operacional (variável retirada } \\
\text { da Demonstração do Resultado do } \\
\text { Exercício) }\end{array}$ & $\begin{array}{c}\text { Pontuação do Ranking da CBF (Calculado } \\
\text { a partir da Convenção de Pontos da } \\
\text { CBF, para campeonatos nacionais e } \\
\text { internacionais) }\end{array}$ \\
\hline
\end{tabular}

Fonte: Elaboração própria.

Quanto à questão esportiva, o novo ranking da CBF estabelece pontuações diversas para a colocação dos clubes nos seus campeonatos, por exemplo, o campeão da Série $A$ do Campeonato Brasileiro recebe uma pontuação bem maior do que o primeiro colocado na Série B, e assim por diante. Torna-se, assim, uma boa Proxy, pois estabelece para essa variável uma divisão melhor entre os clubes, do que seria a variável aproveitamento de pontos, ou pontos conquistados no ano, como acontece em pesquisas internacionais. A formatação de pontuação proposta pela CBF se encontra no sítio da Internet da instituição.

Com o cálculo dos indicadores de eficiência, os mesmos serão considerados como variável dependente de um modelo de Regressão Tobit, como forma de avaliar quais variáveis possuem alguma relação de significância com os indicadores de eficiência. Segundo Hoff (2007) e Sueyoshi, Goto e Omi (2010), a Regressão Tobit é considerada como o segundo estágio da DEA, por conta da característica 
truncada da variável eficiência. O modelo de regressão é indicado na equação 1, apresentando também as variáveis dependentes escolhidas para este estudo:

IDEA $=\beta 0+\beta 1 X 1+\beta 2 X 2 .+\beta 3 X 3+\beta 4 X 4+\beta 5 X 5+\beta 6 X 6+\beta 7 X 7+\beta 8 X 8+\varepsilon$

Onde:

- IDEA é a variável dependente - indicadores de eficiência, calculados a partir da Super-eficiência, utilizando o insumo e os produtos descritos no Quadro 2;

- $\beta 0, \beta 1, \beta 2, \beta 3, \beta 4, \beta 5, \beta 6, \beta 7$ e $\beta 8$ são os coeficientes estimados da regressão;

-X1 - Grau de Endividamento, calculada a partir da razão entre o Passivo (Circulante + Não-Circulante) e o Ativo Total;

-X2 - Dummy para clubes que conquistaram títulos no período (1 para conquista e 0 para os demais);

- X3 - Dummy para a diferença de divisões do campeonato brasileiro entre os clubes (1 para times na Série A e 0 para os demais);

- X4 - Dummy para os 12 grandes clubes do país (Atlético-MG, Botafogo, Corinthians, Cruzeiro, Flamengo, Fluminense, Grêmio, Internacional, Palmeiras, Santos, São Paulo e Vasco);

- X5 - Dummy para acesso de divisão e vaga na Copa Libertadores da América (1 para Acesso e Libertadores e 0 para os demais);

- X6 - Dummy para rebaixados (1 para rebaixamento e 0 para os demais);

-X7 - Aproveitamento de pontos durante o ano, em todos os campeonatos (Pontos conquistados/ pontos disputados);

- X8 - Dummy para Passivo à Descoberto (1 para os times que apresentam o Patrimônio Líquido negativo e 0 para Patrimônio Líquido positivo);

- $\varepsilon$ é o fator de erro da regressão.

O"Grau de Endividamento" é uma proxy que evidencia as dificuldades financeiras dos clubes de futebol do país. Tem o intuito de investigar se a eficiência na geração dos resultados (financeiro e esportivo) está ligada ao endividamento. Halkos e Tzeremes (2013) escolheram como proxy de endividamento o próprio montante de passivo do clube. No caso desta pesquisa, optou-se por utilizar o indicador citado, como uma melhor forma de evidenciar o endividamento, independente do tamanho do clube. A pesquisa citada não encontrou influência significativa entre o endividamento e os indicadores de eficiência. Nesta, espera-se que exista uma relação negativa entre a eficiência e o indicador, ou seja, quanto maior o grau de endividamento, menor a eficiência.

O"Passivo a Descoberto" representa os clubes que possuem Patrimônio líquido negativo. Tomando como base o ano de 2012, 17 clubes da amostra apresentaram tal situação. Neste caso, espera-se a mesma relação apontada para o grau de endividamento, já que um grau de endividamento acima de $100 \%$ equivale à entidade estar com passivo a descoberto.

As demais variáveis representam características esportivas do futebol. Para "Títulos", “Divisão", "12 grandes", "Acesso e Libertadores" e "Aproveitamento de Pontos", espera-se que as mesmas se comportem de forma positiva em relação à eficiência calculada. A conquista de "Títulos", como explicitado na revisão da literatura, pode acarretar em um aumento de receita, que é um dos outputs desta pesquisa.

O mesmo pensamento pode ser atribuído para "Acesso e Libertadores" e"Aproveitamento de Pontos". Ou seja, quanto maior o sucesso esportivo maior é a eficiência, esperando-se então um sinal positivo no coeficiente referente às variáveis citadas. Ademais, a "Divisão" do clube pode também ser um fator determinante da eficiência, já que existe uma disparidade entre os clubes de divisões diferentes. No 
caso desta pesquisa, entende-se que clubes de divisões maiores (no caso, a Série A) tem a maior possibilidade de serem mais eficientes.

Já a variável "12 grandes" representa o fator de tamanho dos clubes, destacando os maiores do país, tanto na questão financeira, quanto em sua importância para o mercado brasileiro (Atlético-MG, Botafogo, Cruzeiro, Corinthians, Flamengo, Fluminense, Grêmio, Internacional, Palmeiras, Santos, São Paulo e Vasco). Espera-se que estes clubes se destaquem perante os demais, e obtenha maiores índices de eficiência. Pesquisas como a de Halkos e Tzeremes (2013) e Barros, Assaf e Sá-Earp (2010) não encontraram nenhuma relação entre tamanho (ou valor) do clube e sua eficiência.

Por fim, a variável "Rebaixamento" representa, esportivamente falando, o insucesso maior de um clube na liga nacional. Portanto, ao adicionar esta variável ao modelo, pretende-se avaliar se existe alguma relação entre a mesma e a eficiência, entendendo-se que o rebaixamento dos clubes provoca uma queda nos indicadores de eficiência.

As variáveis relacionadas ao aspecto esportivo foram calculadas ou avaliadas a partir da consulta de tabelas e base de dados na internet dos campeonatos estaduais, nacionais e internacionais disputados pelas equipes da amostra nos anos estudados.

Estabelecido os regressores, os resultados esperados dos sinais dos coeficientes da regressão são apresentados na Tabela 1, de acordo com o apresentado na equação 1, e explicado logo depois.

Para calcular a eficiência, os dados foram trabalhados no programa EMS - Efficiency Measurement System ${ }^{\oplus}$, e, para a Regressão Tobit, foi usado o pacote estatístico gratuito Gretl ${ }^{\circledR}$.

Tabela 1: Sinais esperados dos coeficientes

\begin{tabular}{|c|c|}
\hline Variáveis & Sinal Esperado \\
\hline Grau de Endividamento & - \\
\hline Títulos & + \\
\hline Divisão & + \\
\hline 12 clubes grandes & + \\
\hline Acesso e Libertadores & + \\
\hline Rebaixamento & - \\
\hline Aproveitamento & + \\
\hline Passivo à Descoberto & - \\
\hline
\end{tabular}

Fonte: Elaboração própria.

\section{ANÁLISE DE DADOS}

\subsection{ESTATÍSTICA DESCRITIVA DAS VARIÁVEIS}

Neste sub-tópico, será demonstrada a estatística descritiva das variáveis estudadas, por questões de espaço, os dados monetários e o Ranking da CBF serão apresentados na tabela 6 nos anexos dessa pesquisa. De acordo com a tabela 2, o clube com a maior despesa do departamento de futebol da amostra em todos os anos analisados é o Sport Club Corinthians Paulista, enquanto o menor é o ASA-AL, nos anos de 2010 e 2011, e Vila Nova-GO, em 2012. Observando a média, nota-se que durante o período, as despesas aumentaram consideravelmente, passando de R\$ 41,4 milhões em 2011 para R\$ 61,9 milhões em 2012. O desvio-padrão mostra os desvios em torno da média entre os dados da amostra, 
principalmente no ano de 2012 , no valor de $\mathrm{R} \$ 59,6$ milhões. Os clubes estudados são de tamanhos variados, o que pode enviesar alguns resultados.

Como já apresentado na descrição das despesas do futebol, o Corinthians também é o maior clube brasileiro em geração de receitas e o ASA-AL, nos anos de 2010 e 2011, e Vila Nova-GO, em 2012, são os menores da amostra. Já a variável "pontuação" se refere ao desempenho esportivo durante cada temporada. Vale salientar que essa variável depende, obviamente, do desempenho do clube dentro de campo e do nível dos campeonatos. Por isso, considerações sobre variação de um ano para outro, ou elucidar números específicos torna-se uma tarefa difícil. O Palmeiras, por exemplo, mesmo rebaixado para a segunda divisão do campeonato brasileiro, sagrou-se campeão da Copa do Brasil, e, portanto, obteve uma pontuação considerável, em relação aos outros clubes, no ano de 2012.

Tabela 2: Estatística Descritiva das variáveis do modelo DEA (variáveis financeiras em $R \$$ mil)

\begin{tabular}{|c|c|c|c|c|}
\hline Variáveis & Est. Descritiva & 2010 & 2011 & 2012 \\
\hline Despesa & $\begin{array}{l}\text { Média } \\
\text { D. Padrão } \\
\text { Máximo } \\
\text { Mínimo }\end{array}$ & $\begin{array}{r}41.416 \\
40.899 \\
153.399 \text { (Corint.) } \\
23.011 \text { (ASA-AL) }\end{array}$ & $\begin{array}{r}50.040 \\
48.032 \\
197.386 \text { (Corint.) } \\
3.381 \text { (ASA-AL) }\end{array}$ & $\begin{array}{r}61.933 \\
59.570 \\
233.268 \text { (Corint.) } \\
923 \text { (Vila Nova) }\end{array}$ \\
\hline $\begin{array}{c}\text { Receita } \\
\text { Operacional }\end{array}$ & $\begin{array}{l}\text { Média } \\
\text { D. Padrão } \\
\text { Máximo } \\
\text { Mínimo }\end{array}$ & $\begin{array}{r}52.773 \\
55.836 \\
212.633 \text { (Corint.) } \\
5.136 \text { (ASA-AL) }\end{array}$ & $\begin{array}{r}67.473 \\
71.545 \\
290.489 \text { (Corint.) } \\
4.745 \text { (ASA-AL) } \\
\end{array}$ & $\begin{array}{r}88.632 \\
91.222 \\
358.512 \text { (Corint.) } \\
4.215 \text { (Vila Nova) } \\
\end{array}$ \\
\hline Pontuação & $\begin{array}{l}\text { Média } \\
\text { D. Padrão } \\
\text { Máximo } \\
\text { Mínimo }\end{array}$ & $\begin{array}{r}570 \\
333 \\
1200 \text { (Flu.) } \\
60 \text { (Santa Cruz) }\end{array}$ & $\begin{array}{r}580 \\
329 \\
1.240 \text { (Vasco) } \\
80 \text { (Santa Cruz) }\end{array}$ & $\begin{array}{r}615 \\
328 \\
1.290 \text { (S. Paulo) } \\
112 \text { (Santo André) }\end{array}$ \\
\hline $\begin{array}{l}\text { Grau de } \\
\text { Endividamento (\%) }\end{array}$ & $\begin{array}{l}\text { Média } \\
\text { D. Padrão } \\
\text { Máximo } \\
\text { Mínimo }\end{array}$ & $\begin{array}{r}124 \\
99 \\
438 \text { (Botafogo) } \\
22 \text { (Paraná) }\end{array}$ & $\begin{array}{r}156 \\
202 \\
1211 \text { (G. Barueri) } \\
17 \text { (Sport) }\end{array}$ & $\begin{array}{r}112 \\
081 \\
2072 \text { (G. Barueri) } \\
17 \text { (Sport) }\end{array}$ \\
\hline Aproveit. (\%) & $\begin{array}{l}\text { Média } \\
\text { D. Padrão } \\
\text { Máximo } \\
\text { Mínimo }\end{array}$ & $\begin{array}{r}53 \\
8 \\
68 \text { (Coritiba) } \\
38 \text { (Guarani) }\end{array}$ & $\begin{array}{r}52 \\
9 \\
68 \text { (Coritiba) } \\
32 \text { (Santo André) }\end{array}$ & $\begin{array}{r}52 \\
10 \\
70 \text { (Goiás) } \\
26 \text { (G. Barueri) }\end{array}$ \\
\hline \multicolumn{5}{|c|}{ Variáveis Dicotômicas (Frequência de valores "1") } \\
\hline Variáveis & Est. Descritiva & 2010 & 2011 & 2012 \\
\hline Títulos & Frequência & 11 & 12 & 12 \\
\hline Divisão & Frequência & 18 & 18 & 18 \\
\hline 12 Grandes & Frequência & 12 & 12 & 12 \\
\hline Acesso e Lib. & Frequência & 12 & 11 & 10 \\
\hline Rebaixamento & Frequência & 5 & 4 & 6 \\
\hline Pass. à Desc. & Frequência & 16 & 16 & 17 \\
\hline
\end{tabular}

Fonte: Elaboração pelos autores 
O grande dilema de pesquisas como esta é o desvio dos dados, principalmente quando a amostra possui entidades de tamanhos muito diferentes. Entretanto, devem-se encontrar formas para minimizar os prejuízos nos resultados que porventura ocorram por tais circunstâncias. A Análise Envoltória de Dados pode auxiliar os pesquisadores nesse sentido, já que, além de analisar a eficiência, levando em conta todos os dados da amostra e o tamanho de suas DMUs, funciona também como uma ferramenta para transformar os dados e o número de variáveis em apenas um indicador.

A Tabela 2 ainda evidencia o Grau de Endividamento. Em todos os anos estudados, o Grêmio Barueri, em 2012, apontou o maior índice (2.072\%). Isso quer dizer que a dívida é $2.072 \%$ maior do que o Ativo, ou seja, um endividamento alto para qualquer tipo de empresa. A maioria dos indicadores de grau de endividamento se apresentaram maiores que 100\%, ou valores próximos. Entende-se que são as entidades que apresentam em suas demonstrações o passivo a descoberto. Fato esse ocorrido devido aos montantes de prejuízos acumulados dos clubes de futebol do Brasil ao longo dos anos. A frequência apresentada logo abaixo demonstra que 16 clubes estavam nesta situação em 2010 e 2011 , e 17 em 2012.

Por fim, Aproveitamento de Pontos, uma das variáveis independentes e relacionada ao desempenho esportivo, apresentou praticamente a mesma média nos anos estudados, sendo que os maiores valores foram os do Coritiba (2010 e 2011) e Goiás (2012). Vale salientar que esta variável não representa a conquista de títulos, que é o fator mais importante no esporte, e sim um desempenho como um todo de uma temporada, incorporando todos os campeonatos (independente da importância dos mesmos) durante $o$ ano.

Em referência as frequências das variáveis dicotômicas, destaca-se a variável Títulos que aponta a quantidade de clubes da amostra que se tornaram campeões ao menos uma vez em cada ano analisado (11, 12 e 12 clubes, para os anos 2010, 2011 e 2012, respectivamente). No caso da Divisão, a amostra possui 18 clubes na primeira divisão em cada ano, obviamente não sendo os mesmos. Acesso e Libertadores demonstrou uma queda, saindo de 12, em 2010, para 10, em 2012. E, por fim, a variável Rebaixamento demonstra que poucos clubes da amostra passaram por tal situação.

\subsection{CÁLCULO DOS INDICADORES DE EFICIÊNCIA}

Diante do exposto na metodologia e nos capítulos anteriores, a Tabela 3 apresenta os resultados do modelo de Super-eficiência DEA.

Para o ano de 2010, o Vitória foi o clube mais eficiente durante o período, seguido de Flamengo, Fluminense, Corinthians, São Paulo e ASA-AL. Os clubes citados são àqueles que atingiram a unidade ou a ultrapassaram. Caso fosse calculada a eficiência padrão da DEA, as DMUs que apresentassem valores iguais ou maiores que um no modelo de super-eficiência estariam empatadas na unidade. Os três últimos clubes do ranking do ano de 2010 são Criciúma, Ponte Preta e Paraná.

Em relação a 2011, foram eficientes o Santa Cruz, Corinthians, Avaí, Vasco, Flamengo e ASA-AL, enquanto no ano de 2012, ASA-AL, Fluminense, Corinthians, São Paulo, Avaí, Palmeiras, Goiás, Santa Cruz e Vila Nova atingiram ou ultrapassaram a unidade. Ademais, deve-se salientar que, no retorno variável de escala, a DEA tende a considerar como eficientes a menor e a maior DMU da amostra. 
Tabela 3: Indicadores de Super-Eficiência

\begin{tabular}{|c|c|c|c|c|c|c|c|}
\hline Times & 2010 & 2011 & 2012 & Times & 2010 & 2011 & 2012 \\
\hline$A B C-R N$ & 0,62 & 0,72 & 0,58 & Grêmio Bar. & 0,62 & 0,80 & 0,61 \\
\hline América-MG & 0,59 & 0,88 & 0,55 & Guarani & 0,72 & 0,74 & 0,62 \\
\hline ASA-AL & 1,00 & 1,00 & 1,60 & Internacional & 0,96 & 0,84 & 0,92 \\
\hline Atlético-MG & 0,80 & 0,64 & 0,73 & Joinville & 0,48 & 0,66 & 0,61 \\
\hline Atlético-PR & 0,73 & 0,80 & 0,41 & Náutico & 0,55 & 0,94 & 0,85 \\
\hline Avaí & 0,70 & 1,27 & 1,06 & Palmeiras & 0,83 & 0,79 & 1,05 \\
\hline Bahia & 0,52 & 0,71 & 0,86 & Paraná & 0,44 & 0,61 & 0,88 \\
\hline Botafogo & 0,71 & 0,66 & 0,65 & Ponte Preta & 0,46 & 0,65 & 0,86 \\
\hline Bragantino & 0,67 & 0,86 & 0,67 & Portuguesa & 0,59 & 0,90 & 0,96 \\
\hline Corinthians & 1,09 & 1,29 & 1,27 & Santa Cruz & 0,72 & 1,66 & 1,00 \\
\hline Coritiba & 0,58 & 0,95 & 0,92 & Santo André & 0,50 & 0,63 & 0,58 \\
\hline Criciúma & 0,45 & 0,87 & 0,87 & Santos & 0,99 & 0,93 & 0,86 \\
\hline Cruzeiro & 0,91 & 0,84 & 0,63 & São Caetano & 0,70 & 0,71 & 0,59 \\
\hline Figueirense & 0,49 & 0,73 & 0,57 & São Paulo & 1,02 & 0,98 & 1,18 \\
\hline Flamengo & 1,20 & 1,05 & 0,77 & Sport & 0,56 & 0,69 & 0,79 \\
\hline Fluminense & 1,17 & 0,92 & 1,31 & Vasco & 0,80 & 1,21 & 0,79 \\
\hline Goiás & 0,64 & 0,57 & 1,00 & Vila Nova & 0,84 & 0,74 & 1,00 \\
\hline Grêmio & 0,91 & 0,72 & 0,85 & Vitória & 1,33 & 0,79 & 0,79 \\
\hline Média & 0,75 & 0,86 & 0,84 & Máximo & Vitória & S. Cruz & ASA-AL \\
\hline Desv. Padrão & 0,23 & 0,22 & 0,24 & Mínimo & Paraná & Goiás & Atl.-PR \\
\hline
\end{tabular}

Fonte: Elaboração pelos autores

Com o cálculo dos indicadores de eficiência, alguns comentários podem ser feitos sobre os mesmos. O ASA-AL foi eficiente em todos os anos, mas deve-se salientar que o clube é o menor da amostra nos dois primeiros anos, o que pode ter beneficiado-o pelas restrições do modelo BCC. Pelo mesmo motivo, mas por ser o maior clube da amostra, o Corinthians foi eficiente nos três anos. Mas, neste caso, o Corinthians teve o centenário de nascimento no ano de 2010 e, no mesmo ano, ainda contava com o jogador Ronaldo, o que é uma grande fonte de receitas, principalmente de patrocínios. Em 2011, o clube foi campeão brasileiro e, em 2012, o clube sagrou-se campeão da Copa Libertadores da América pela primeira vez, além de ter conquistado o bicampeonato mundial no mesmo ano.

Continuando com a análise da Tabela 3, o Coritiba apresentou um crescimento de eficiência entre 2010 e 2011, mantendo o patamar do segundo ano em 2012. Uma explicação para este fato pode ser o"bi vice-campeonato" da Copa do Brasil, o que provoca um bom indicador de desempenho esportivo, como também o aumento de receitas. Já o Fluminense apresentou eficiência justamente nos anos em que se sagrou campeão brasileiro (2010 e 2012), como o Goiás, que foi campeão da Série B em 2012.

Uma das curiosidades dos resultados apontados pela Tabela 3 deve-se ao resultado de eficiência do Palmeiras em 2012. O clube paulista foi rebaixado para Série B do Campeonato Brasileiro do ano citado, mas conquistou a Copa do Brasil, assim alavancando o resultado esportivo, como também as receitas.

Por fim, Santa Cruz foi eficiente nos anos em que conseguiu acesso para as divisões superiores; o Santos não foi eficiente em nenhum dos anos, apesar do fator "Neymar" e dos títulos conquistados no período analisado. Talvez pelo Ranking da CBF não pontuar os campeonatos estaduais, e não dar 
pontuações ponderadas pelas posições conquistadas na Libertadores; Vasco e Vitória foram eficientes nos anos que foram campeão e vice, respectivamente, da Copa do Brasil.

A Tabela 4 apresenta o número de citações que as DMUs eficientes receberam como benchmarkings para as DMUs ineficientes.

Tabela 4: Citações de Referências dos clubes eficientes

\begin{tabular}{|c|c|r|r|r|r|r|r|}
\hline Times & 2010 & 2011 & 2012 & Times & 2010 & 2011 & 2012 \\
\hline ASA-AL & 20 & 17 & 11 & Palmeiras & - & - & 9 \\
\hline Avaí & - & 15 & 11 & Santa Cruz & - & 8 & 3 \\
\hline Corinthians & 7 & 5 & 2 & São Paulo & 0 & - & 7 \\
\hline Flamengo & 22 & 6 & - & Vasco & - & 28 & - \\
\hline Fluminense & 10 & - & 24 & Vila Nova & - & - & 3 \\
\hline Goiás & - & - & 4 & Vitória & 16 & - & - \\
\hline
\end{tabular}

O ASA-AL recebeu 48 citações como referência para outras DMUs, entre os períodos estudados, porém não foi o mais citado em nenhum dos anos. Em 2010, o clube mais referenciado foi o Flamengo, enquanto em 2011 foi o Vasco e Fluminense em 2012. A partir das saídas do EMS, é possível calcular os alvos necessários para se atingir a eficiência. Assim, os resultados destas projeções são apresentados na Tabela 5:

Tabela 5: Projeções de receitas e pontuação para as DMUs ineficientes, com a porcentagem de crescimento necessário para os outputs (receita em $R \$$ mil e, entre parênteses, o percentual de crescimento, em\%)

\begin{tabular}{|c|c|c|c|c|c|c|}
\hline \multirow{2}{*}{ Times } & \multicolumn{2}{|c|}{2010} & \multicolumn{2}{|c|}{2011} & \multicolumn{2}{|c|}{2012} \\
\hline & Receita & Pontos & Receita & Pontos & Receita & Pontos \\
\hline$A B C-R N$ & $10.073(61)$ & $333(66)$ & $17.225(43)$ & $358(40)$ & $23.460(70)$ & $424(71)$ \\
\hline Amér.-MG & 23768 (69) & 473 (69) & 39.410 (67) & $624(42)$ & $40.584(82)$ & $480(82)$ \\
\hline ASA-AL & Eficiente & Eficiente & Eficiente & Eficiente & Eficiente & Eficiente \\
\hline Atlét.-MG & $116.142(25)$ & $1.110(25)$ & $156.714(57)$ & $1.122(96)$ & $\begin{array}{r}222.861 \\
(37)\end{array}$ & $1.151(37)$ \\
\hline Atlét.-PR & $69.491(36)$ & $1.030(37)$ & $88.760(44)$ & $1.072(25)$ & $\begin{array}{r}152.977 \\
(144)\end{array}$ & 1.197 (299) \\
\hline Avaí & $45.951(44)$ & $965(44)$ & Eficiente & Eficiente & Eficiente & Eficiente \\
\hline Bahia & $39.430(92)$ & 769 (92) & $55.042(49)$ & $954(40)$ & $\begin{array}{r}106.073 \\
(59)\end{array}$ & $1.016(17)$ \\
\hline Botafogo & $74.976(42)$ & $915(42)$ & $91.826(56)$ & $1.082(50)$ & $\begin{array}{r}187.873 \\
(53) \\
\end{array}$ & $1.127(53)$ \\
\hline Bragantino & $10.316(89)$ & $398(51)$ & $7.432(14)$ & 313 (15) & $15.014(43)$ & 353 (47) \\
\hline Corinthians & Eficiente & Eficiente & Eficiente & Eficiente & Eficiente & Eficiente \\
\hline Coritiba & $52.758(72)$ & $858(72)$ & 85.695 (29) & $1.061(5)$ & $\begin{array}{r}114.898 \\
(39)\end{array}$ & 1.052 (9) \\
\hline Criciúma & $16.244(118)$ & $361(141)$ & $25.738(14)$ & 273 (14) & 24.315 (18) & 488 (16) \\
\hline Cruzeiro & $112.133(11)$ & $1.148(10)$ & 152.918 (19) & $1.145(33)$ & $\begin{array}{r}192.371 \\
(60)\end{array}$ & $1.149(60)$ \\
\hline
\end{tabular}




\begin{tabular}{|c|c|c|c|c|c|c|}
\hline Figueirense & $34.128(102)$ & 649 (103) & $55.783(37)$ & $738(38)$ & 71.749 (75) & $755(75)$ \\
\hline Flamengo & Eficiente & Eficiente & Eficiente & Eficiente & $\begin{array}{r}274.673 \\
(30) \\
\end{array}$ & $1.172(30)$ \\
\hline Fluminense & Eficiente & Eficiente & 94.891 (18) & $1.093(9)$ & Eficiente & Eficiente \\
\hline Goiás & $63.741(110)$ & $922(44)$ & $31.527(70)$ & $780(73)$ & Eficiente & Eficiente \\
\hline Grêmio & $114.267(11)$ & $1.116(10)$ & $141.394(38)$ & 1.239 (38) & $\begin{array}{r}210.032 \\
(18)\end{array}$ & $1.238(18)$ \\
\hline G. Barueri & $28.076(61)$ & $698(62)$ & $26.216(23)$ & $320(23)$ & $12.966(67)$ & $354(64)$ \\
\hline Guarani & $39.916(74)$ & $898(39)$ & $19.111(32)$ & $469(35)$ & $41.632(63)$ & $527(63)$ \\
\hline Inter & $174.864(5)$ & $978(4)$ & 223.148 (19) & 1.129 (19) & 274.014 (8) & $1.019(12)$ \\
\hline Joinville & $12.541(100)$ & 344 (392) & $15.356(54)$ & $306(53)$ & $24.143(60)$ & $439(62)$ \\
\hline Náutico & 24.006 (106) & $629(83)$ & $20.871(8)$ & $560(8)$ & 48.545 (18) & 701 (18) \\
\hline Palmeiras & $143.369(20)$ & $1.102(21)$ & $183.467(26)$ & $1.135(26)$ & Eficiente & Eficiente \\
\hline Paraná & 36.586 (183) & 842 (129) & $30.994(62)$ & $557(62)$ & $17.491(15)$ & $520(14)$ \\
\hline P. Preta & 40.925 (115) & $521(117)$ & $25.256(55)$ & $615(54)$ & $51.330(71)$ & $792(16)$ \\
\hline Portuguesa & $40.928(66)$ & $475(72)$ & $32.520(12)$ & $500(11)$ & $45.048(4)$ & $692(4)$ \\
\hline S. Cruz & $8.838(44)$ & 327 (445) & Eficiente & Eficiente & Eficiente & Eficiente \\
\hline S. André & $24.881(97)$ & 447 (99) & $13.979(56)$ & $183(58)$ & $13.389(69)$ & $191(71)$ \\
\hline Santos & $117.565(1)$ & $1.140(2)$ & $203.364(8)$ & $1.003(10)$ & $\begin{array}{r}231.062 \\
(17) \\
\end{array}$ & $1.084(17)$ \\
\hline S. Caetano & $27.352(43)$ & $413(61)$ & $35.774(41)$ & $334(41)$ & $55.659(71)$ & $471(71)$ \\
\hline São Paulo & Eficiente & Eficiente & $228.864(2)$ & $1.061(12)$ & Eficiente & Eficiente \\
\hline Sport & $52.439(82)$ & $854(81)$ & $68.612(46)$ & $579(75)$ & $\begin{array}{r}100.101 \\
(25)\end{array}$ & $810(46)$ \\
\hline Vasco & $104.566(25)$ & $1.137(26)$ & Eficiente & Eficiente & $\begin{array}{r}174.756 \\
(25) \\
\end{array}$ & $1.199(26)$ \\
\hline Vila Nova & $7.604(11)$ & $321(39)$ & $11.595(37)$ & $303(35)$ & Eficiente & Eficiente \\
\hline Vitória & Eficiente & Eficiente & $42.530(24)$ & $406(25)$ & $66.852(28)$ & $856(26)$ \\
\hline
\end{tabular}

A Tabela 5 aponta a necessidade de crescimento de receita e pontuação para as DMUs ineficientes alcançarem a eficiência. Traçar perfis e comentários pormenorizados torna-se difícil neste momento, por diversos motivos, entre eles a quantidade de dados e a questão da própria programação matemática atribuir estes valores. Entretanto, funciona como indicadores da necessidade de os clubes buscarem novas fontes de receitas, isso, claro, tratando apenas do aspecto financeiro. Já no aspecto esportivo, a busca em aumentar a sua pontuação está ligada diretamente com a perda de pontuação do outro, o que torna ainda mais complicado uma análise deste tipo.

Porém, a Tabela 5 corrobora os resultados apresentados na Tabela 3, onde se demonstra o aumento da média do nível de eficiência. As projeções apontam a necessidade do aumento dos outputs em 100\% ou mais em alguns clubes, fato este minimizado nos anos posteriores. Além do aumento da quantidade de equipes que se tornaram eficientes no ano de 2012. Assim, pode-se estabelecer que há indícios de que o nível de eficiência dos clubes de futebol brasileiros vêm aumentando ao longo do tempo. As causas deste aumento no nível de eficiência não entram no escopo da pesquisa em si, porém pode ser uma nova fonte de pesquisas vindouras. 


\subsection{MODELO DE REGRESSÃO TOBIT E SIGNIFICÂNCIA DAS VARIÁVEIS}

Para atender o objetivo proposto da pesquisa, que é estabelecer quais variáveis são significantes para explicar a eficiência obtida, o modelo de regressão será o Tobit. Os dados foram trabalhados no Gretl. No software, não foi imposta limitação à direita, e foi utilizada robustez para os erros-padrão. A Tabela 6 mostra os resultados da regressão, sendo a variável dependente o índice DEA.

A Tabela 6 mostra que, de acordo com p-valor da estatística $Z$ das variáveis, apenas as dummies de "Títulos"e de "Divisão" influenciam os indicadores de eficiência. Os sinais dos coeficientes são positivos, o que corrobora o fato de que os clubes que conquistam títulos e os clubes da primeira divisão são mais eficientes. Partindo do pressuposto que um dos outputs utilizados nesta pesquisa é a receita (com a orientação ao produto), pode-se inferir que a maximização de títulos é o principal objetivo de um clube de futebol, pois, de acordo com os resultados do modelo de regressão, os clubes que foram mais eficientes o foram quando conquistaram títulos. No caso, pode-se inferir que as receitas são maximizadas (e os pontos da CBF também) quando da ocorrência deste fato. Os recursos são direcionados para isto e, como abordado anteriormente, sem a parcimônia no controle de gastos.

Tabela 6: Resultado do modelo de regressão Tobit

\begin{tabular}{|c|c|c|c|c|c|c|c|c|}
\hline \multirow{2}{*}{ Variável } & \multirow{2}{*}{ Coefic. } & \multirow{2}{*}{ Erro Pad. } & \multirow{2}{*}{ Z } & \multirow{2}{*}{ P-Valor } & \multirow{2}{*}{ Sig } & \multirow{2}{*}{ VIF } & \multicolumn{2}{|c|}{ Inter. Conf. (95\%) } \\
\hline & & & & & & & Menor & Maior \\
\hline Constante & 0,805 & 0,146 & 5,509 & $3,62 e-8$ & $* * *$ & & 0,518 & 1,091 \\
\hline $\begin{array}{c}\text { G } r \text { a } \mathrm{u} \quad \mathrm{d} \text { e } \\
\text { Endividam. }\end{array}$ & $-8,8 e-5$ & $5,6 e-5$ & $-1,573$ & 0,116 & & 1,364 & $-2,0 e-4$ & $2,2 e-5$ \\
\hline Dummy Título & 0,181 & 0,048 & 3,799 & 0,000 & $* * *$ & 1,508 & 0,088 & 0,275 \\
\hline Dummy Divisão & 0,111 & 0,047 & 2,341 & 0,019 & ** & 2,544 & 0,018 & 0,204 \\
\hline $\begin{array}{c}\text { D u m m y } 12 \\
\text { Grandes }\end{array}$ & 0,029 & 0,051 & 0,562 & 0,574 & & 2,613 & $-0,071$ & 0,128 \\
\hline D. Acesso e Libert. & 0,063 & 0,050 & 1,254 & 0,210 & & 1,667 & $-0,036$ & 0,162 \\
\hline $\begin{array}{l}\text { D u m m y } \\
\text { Rebaixamento }\end{array}$ & $-0,006$ & 0,059 & $-0,099$ & 0,921 & & 1,543 & $-0,121$ & 0,109 \\
\hline $\begin{array}{c}\text { Dummy Pass. } \\
\text { Desc. }\end{array}$ & 0,056 & 0,044 & 1,254 & 0,210 & & 1,245 & $-0,031$ & 0,142 \\
\hline $\begin{array}{l}\text { D u m m y } \\
\text { Aproveitam. }\end{array}$ & $-0,003$ & 0,003 & $-0,975$ & 0,330 & & 2,791 & $-0,008$ & 0,003 \\
\hline \multicolumn{9}{|c|}{ Teste da normalidade dos resíduos - Estatística de teste: Qui-quadrado(2) = 53.0826} \\
\hline & & & *Signific & $1 \%$ & * Sign & icante a & & ificante a $10 \%$ \\
\hline
\end{tabular}

A variável "Títulos" representa pelo menos uma conquista na temporada analisada. Entretanto, a variável "Ranking da CBF", que compõe um dos outputs do modelo DEA escolhido, demonstra, em alguns casos, a mesma conquista de títulos evidenciada pela variável citada anteriormente. Neste caso, a única diferença entre as duas seria o fato de que o Ranking da CBF não atribui pontuações por posições aos campeonatos internacionais, como também aos estaduais. Por isso, a variável "Títulos" 
foi construída com o intuito de evidenciar a conquista de títulos destes campeonatos não abarcados pelo Ranking da CBF.

Em relação ao resultado significante desta Proxy, este pode ter ocorrido pela paridade entre as duas variáveis. Partindo do pressuposto de que a DEA escolhe os melhores variáveis para se calcular a eficiência, os clubes que obtiveram bons resultados esportivos (em comparação com a receita) se tornaram mais eficientes e, em alguns casos, acompanha a variável "Títulos".

Os autores desta pesquisa retiraram a variável "Títulos" e construíram um modelo com as demais variáveis. Os resultados se comportaram da mesma maneira, com a variável "divisão" tornando-se a única significante.

A variável "Acesso e Libertadores" não mostrou significância com a eficiência calculada. Em diversos casos, o acesso ou a vaga da Libertadores é um título para determinado clube. Entretanto, pelas limitações da metodologia, talvez esta questão não possa ser bem mensurada. O mesmo pensamento pode ser traçado para a variável "Rebaixamento", porém com o sentido invertido. Entende-se que, em pesquisas futuras, estas duas variáveis possam analisadas de forma pormenorizada, no intuito de meIhorar a elucidação sobre o impacto das variáveis citadas no desempenho geral dos clubes.

No caso da divisão, considera-se aqui que os clubes que pertencem a Série A do Campeonato Brasileiro são mais eficientes que clubes de divisões menores. Neste caso, pode ser comentado que clubes de menor porte podem sofrer com problemas financeiros e a não geração de receitas suficientes (ou pontuação suficiente) para se tornar eficientes, questão que pode ser visualizada na Tabela 5, onde se apresentam a variação de outputs necessários para a eficiência. Ainda, então, subtende-se que os maiores clubes são os mais eficientes, pois a maioria deles, de acordo com a amostra analisada, pertencem a Série $A$.

Continuando com a análise, o "Grau de Endividamento" não apresentou significância estatística com os indicadores de eficiência, ratificando os achados de Halkos e Tzeremes (2013). Um dos motivos que podem estar ligados ao resultado é a formatação do modelo DEA, com o retorno variável de escala. Outro ponto a ser comentado é que o modelo usado utiliza variáveis operacionais, incluindo uma variável esportiva, o que pode enviesar esta relação. Mesmo assim, esperava-se um resultado diferente do encontrado, pois, na teoria, a boa gestão dos clubes (no tocante a parte financeira) poderia diminuir o endividamento.

Ainda na questão do Grau de Endividamento, mesmo não existindo uma relação entre este e a eficiência, entende-se que os clubes gastam de forma demasiada os seus recursos, isso quando não gastam aqueles que não possuem. No caso, a significância da variável "Títulos" dá a entender que os clubes investem recursos desnecessários para a conquista dos mesmos e, obtendo-os, encontra-se a eficiência, não se preocupando assim com a utilização eficiente dos recursos. As considerações para o "Grau de Endividamento" podem ser discutidas também para a variável “Passivo a Descoberto”. 
A variável Dummy "12 Grandes" é a Proxy representativa do tamanho dos clubes, que não mostrou significância, assim como os trabalhos de Halkos e Tzeremes (2013) e Barros, Assaf e Sá-Earp (2010). Neste caso, o modelo BCC pode ter sido a motriz da não significância, já que o modelo de retornos variáveis de escala aponta a eficiência de acordo com o tamanho das DMUs. Além disso, pela questão de "concorrência" entre as equipes (no sentido esportivo) os times grandes, em sua maioria, não seriam eficientes, como apontado na Tabela 4, onde alguns, como Fluminense e Corinthians, são referências para os demais que estão na mesma escala de tamanho. Por isso, como os clubes maiores praticamente são comparados entre si, a metodologia utilizada nesta pesquisa não pode estabelecer uma grau de relação entre tamanho e eficiência.

Ademais, a Proxy de desempenho esportivo geral durante a temporada, "Aproveitamento de Pontos", não é estatisticamente significante em relação aos indicadores de eficiência. Subtende-se aqui que, o fato de que, em uma competição o clube lograr êxito e em outra não, pode enviesar os resultados desta variável, já que foram utilizados todos os campeonatos disputados pelas equipes nos anos analisados. Além disso, um dos outputs do modelo de super-eficiência é uma Proxy de desempenho esportivo determinada pela pontuação da CBF, o que pode prejudicar alguma significância que poderia ser encontrada, por conta de sua lógica de construção.

Em relação ao modelo em si, o VIF (Fatores de Inflacionamento da Variância) aponta que nenhuma das variáveis apresenta problemas de colinearidade, já que os valores estão abaixo de 5 . Porém, na questão de normalidade dos resíduos, através do p-valor do teste Qui-quadrado, rejeita-se a hipótese nula de normalidade, pois o mesmo está abaixo de 5\%. Apesar disso, seguindo indicação de Brooks (2002) e de Corrar, Paulo e Dias Filho (2007), de acordo com o teorema do limite central e considerando que foi utilizada uma amostra com mais de 100 observações no total, relaxou-se o pressuposto de normalidade dos resíduos.

\section{CONSIDERAÇÕES FINAIS}

Este estudo procurou analisar a eficiência de clubes de futebol no Brasil, mensurando a eficiência por meio de um modelo DEA-BCC e identificando possíveis determinantes desta eficiência por meio de um modelo de Regressão Tobit, para os anos de 2010, 2011 e 2012.

A dificuldade financeira dos clubes tem como principal evidência o indicador de endividamento escolhido para esta pesquisa. Por ele, demonstra-se o quanto os clubes são endividados, decorrência da falta de eficiência dos gastos absurdos realizados em períodos anteriores. De acordo com os resultados da regressão, o endividamento não influi para determinar os indicadores de eficiência, resultado já encontrado em Halkos e Tzeremes (2013). O fato de não existir significância não impede de salientar o fato de que, os clubes, de acordo com a amostra analisada, possuem uma situação indesejável (vide a estatística descritiva destas variáveis), que pode ser minimizada se os mesmos buscarem atingir uma maior eficiência em suas gestões. No caso desta pesquisa, aparentemente, o nível de eficiência vêm aumentando ao longo dos períodos analisados.

Os resultados desta pesquisa podem ser úteis para novos estudos que tenham como objetivo a análise financeira e operacional dos clubes de futebol do Brasil, que é ainda escassa ao nível nacional, mas já difundida por trabalhos estrangeiros. Além disso, resultados de trabalhos de eficiência podem auxiliar gestores de clubes no controle dos gastos crescentes dos clubes. 
Talvez, o grande problema de um clube de futebol seja a dependência do resultado financeiro perante o resultado esportivo de uma temporada, confirmado pelos resultados da regressão utilizada nesta pesquisa, onde a dummy "Títulos" se mostrou significante para explicar o nível de eficiência de forma positiva. Nos resultados da pesquisa foi discutido que os clubes mais eficientes são aqueles que conquistam títulos, partindo do pressuposto de que a maximização de títulos é o principal objetivo de um clube de futebol. Então, como já comentado, os recursos são direcionados para a conquista esportiva, sem a parcimônia no controle de gastos. Como os clubes sofrem pressões internas (dirigentes e conselheiros) e externas (mídia e torcedores) geralmente por questões passionais do futebol, é notório que a relação entre eficiência e título poderia ocorrer. No caso, as equipes devem tentar de alguma forma minimizar esta dependência, com uma gestão mais profissional, tomando como base a eficiência da utilização de recursos.

Em relação a variável "divisão", cujo comportamento foi significante em relação à eficiência, entende-se aqui que os clubes de divisões inferiores do campeonato brasileiro estão em situação pior do que os clubes tidos como "grandes". Mesmo com a falta de profissionalismo de gestão dos clubes grandes, os mesmos possuem certa "eficiência", pois são times de massa, recebendo vultosos valores de bilheteria, patrocínio, etc. Clubes de menor expressão sofrem - além da má gestão - com a concorrência de torcida dos clubes grandes, o que diminui o seu poder de angariar receitas de diversos tipos.

Os demais resultados já foram discutidos no escopo do artigo. Porém, o que se pode salientar neste momento é o fato de que os retornos variáveis de escala da DEA podem ter enviesado a significância das variáveis, pois o BCC atribui calcula a eficiência de acordo com as diferentes escalas existentes. Daí, alguns times pequenos foram considerados eficientes, em detrimento de alguns clubes grandes. Neste sentido, seria muito difícil a significância, por exemplo, da variável "12 grandes", como também as variáveis "aproveitamento de pontos", "acesso e libertadores" e "rebaixamento"

Como sugestões para pesquisas futuras, pode-se pesquisar, primeiramente, como o resultado esportivo interfere na eficiência financeira dos clubes (e até mesmo em outros indicadores). Como explanado anteriormente, já existe alguns estudos que sugerem que o desempenho financeiro do clube é dependente do resultado dentro de campo. É comum, por exemplo, encontrar estádios vazios quando clubes estão mal em determinado campeonato, ou em colocações intermediárias, quando não há possibilidade de título ou risco de rebaixamento. Acontecendo tal situação, o clube perde receita de bilheteria, por exemplo. Além disso, pode-se abordar também a importância dos títulos para a eficiência. Como exemplo, o titulo da Copa Libertadores da América é mais importante que um título estadual. Essa questão dificilmente é abordada em pesquisas internacionais.

As variáveis utilizadas como independentes para as regressões foram escolhidas baseadas (e adaptadas) de acordo com a revisão da literatura. Entretanto, ainda são necessários outros estudos com outros indicadores criados por novas abordagens e metodologias. Assim sendo, novos estudos podem ser feitos tentando aliar outros indicadores financeiros e esportivos não contemplados por essa pesquisa.

\section{REFERÊNCIAS}

Andersen, P., Petersen, N. C. (1993). A procedure for ranking efficient units in DEA. Management Science, 39 (10), pp. 1261-1264. 
Barajas, A., Fernández-Jardón, C. \& Crolley, L. (maio, 2007). Does sports performance influence revenues and economic results is spanish football?. Munich Personal RePEc Archive, n. 3.234.

Barros, C. P., Assaf, A. \& Sá-Earp, F. (nov., 2010). Brazilian football league technical efficiency: A Simar and Wilson approach. Journal of Sports Economics, 11 (6), pp. 641-651.

Barros, C. P., Corral, J. \& Prieto-Rodriguez, J. (2013). Cost efficiency of French Soccer League clubs using a Finite Mixture Model. Disponível em: <http://www3.uclm.es/profesorado/jcorral/ Trabajando/8d6383_French_Soccer_SF.pdf>. Acesso em: 12 jul. 2013.

Barros, C. P., Garcia-Del-Barrio, P. (fev., 2011). Productivity drivers and market dynamics in the Spanish first division football league. Journal of Productivity Analysis, 35 (1), pp. 5-13.

Barros, C. P., Leach, S. (nov., 2006). Analyzing the performance of the English F.A. Premier League with an Econometric Frontier Model. Journal of Sports Economics, 7 (4), pp. 391-407.

Brooks, C. (2002). Introductory econometrics for finance. Cambridge: Cambridge University Press.

Corrar, L. J., Paulo, E. \& Dias Filho, J. M. (Coords.). (2007). Análise multivariada para cursos de administração, ciências contábeis e economia. São Paulo: Atlas.

Chen, Y. (jun., 2004). Ranking efficient units in DEA. Omega, 32 (3), pp. 213-219.

Dantas, M. G. S. D. (2013). Fatores determinantes da eficiência financeira e esportiva de clubes de futebol do Brasil. 2013. 95 f. Dissertação (Mestrado em Ciências Contábeis) - Programa Multiinstitucional e inter-regional de Pós-graduação em Ciências Contábeis UnB, UFPB, UFRN. Universidade Federal do Rio Grande do Norte, Natal.

Espitia-Escuer, M., García-Cebrián, L. I. (set., 2010). Measurement of the efficiency of football teams in the Champions League. Managerial Decision Economics, 31 (6), pp. 373-386.

García-Sánchez, I. M. (mar., 2007). Efficiency and effectiveness of Spanish football teams: a threestage-DEA approach. Central European Journal of Operations Research, 15 (1), pp. 21-45.

Guzmán, I., Morrow, S. (2007). Measuring efficiency and productivity in professional football teams: evidence from the English Premier League. Central European Journal of Operations Research, 15 (4), pp. 309-328.

Haas, D. J. (ago., 2003). Productive efficiency of english football teams: A Data Envelopment Analysis approach. Managerial and Decision Economics, 24 (5), pp. 403-410.

Haas, D. J. (ago., 2003). Technical efficiency in the Major League Soccer. Journal of Sports Economics, 4 (3), pp. 203-215. 
Halkos, G., Tzeremes, N. (mar., 2013). A Two-Stage Double Bootstrap DEA: The Case of the Top 25 European Football Clubs' Efficiency Levels. Managerial and Decision Economics, 34 (2), pp. 108-115.

Hoff, A. (ago. 2007). Second stage DEA: Comparison of approaches for modelling the DEA score. European Journal of Operational Research, 181 (1), pp. 425-435.

Jardin, M. (jun., 2009). Efficiency of french football clubs and its dynamics. Munich Personal RePEc Archive, n. 19.828.

Kern, A., Schwarzmann, M. \& Wiedenegger, A. (2012). Measuring the efficiency of English Premier League football. Sport, Business and Management: an International Journal. 2 (3), pp. 177-195.

Neale, W. C. (fev., 1964). The Peculiar Economics of Professional Sports: A contribution to the theory of the firm in sporting competition and in market competition. The Quarterly Journal of Economics, 78 (1), pp. 1-14.

Rezende, A. J., Dalmácio, F. Z. \& Salgado, A. L. (maio./ago, 2010). Nível de disclosure das atividades operacionais, econômicas e financeiras dos clubes brasileiros. Contabilidade, Gestão e Governança, Brasília, 13 (2), pp. 36-50.

Rezende, A. J., Facure, C. E. F. \& Dalmácio, F. Z. (2009). Práticas de governança corporativa em organizações sem fins lucrativos. In: CONGRESSO USP CONTROLADORIA E CONTABILIDADE, 9., 2009, São Paulo. Anais... São Paulo: FEA/USP, 2009. Disponível em: <http://www.congressousp.fipecafi. org/web/artigos92009/432.pdf>. Acesso em: 20 abr. 2015.

Silva, J. A. F., Carvalo, F. A. A. (mai./ago, 2009) Evidenciação e desempenho em organizaçãoes desportivas: um estudo empírico sobre clubes de futebol. Revista de Contabilidade e Organizações, 3 (6), pp. 96-116.

Soleimani-Damaneh, J., Hamidi, M. \& Sajadi, N. (jun., 2011). Evaluating the performance of iranian football teams utilizing linear programming. American Journal of Operations Research, 1 (2), pp. 6572.

Sueyoshi, T., Goto, M. \& Omi, Y. (jun., 2010). Corporate governance and firm performance: Evidence from Japanese manufacturing industries after the lost decade. European Journal of Operational Research, 203 (3), pp. 724-736. 